\title{
PROPOSAL OF TERRITORIAL PARAMETERS FOR SEISMIC HAZARD ASSESSMENT IN PISCO, PERU
}

\author{
LUIS IZQUIERDO-HORNA \& PATRICIA ARANIBAR \\ Universidad Tecnológica del Perú, Perú
}

\begin{abstract}
During the last few decades, Peru has experienced numerous natural phenomena (e.g., earthquakes, tsunamis, debris flows, etc.) that have caused considerable economic and human losses. However, the most prevalent phenomenon in Peru is earthquakes due to its geographic location (e.g., Ancash 1970 (7.9 Mw), Pisco 2007 (7.9 Mw), Arequipa 2013 (7.1 Mw), etc.). Therefore, in this research, we focus on improving the techniques for identifying the level of seismic hazard through a set of parameters specific to the territorial conditions. Thus, due to the antecedents presented in the city of Pisco, it has been chosen as a case study. In this sense, a systematic review of parameters and techniques used to determine the level of seismic hazard of a given sector was carried out. Then, the availability of information on the parameters previously identified was evaluated in order to obtain that the most representative variables of the territory are: soil type, slope and soil liquefaction. We consider that this set of parameters is compatible with machine learning techniques or any other method established by the corresponding authorities related to risk and disaster management. Finally, these parameters are applicable and reproducible at any territorial scale.
\end{abstract}

Keywords: hazard, earthquakes, risk and disaster management, Peru.

\section{INTRODUCTION}

The occurrence of a seismic event is a worldwide problem in developing communities since they usually generate large economic and human losses [1]. For this reason, at present, numerous investigations have been carried out in order to identify sectors with a high seismic hazard in order - in this way - to reduce the impacts generated on people and their livelihoods. According to the Pan American Health Organization [2], Peru is one of the countries with the highest seismic activity in the world due to its geographical location. In other words, it is part of the Pacific ring of fire, a sector that experiences approximately $80 \%$ of this type of event in the world. According to the National Institute of Civil Defense (INDECI) [3], the collision of tectonic plates has caused devastating earthquakes like the one of 1970 in Yungay, Ancash (7.8 Mw earthquake). This earthquake caused the death of 66,795 people and completely buried the city of Yungay ( $80 \%$ of the houses were destroyed) [4]. Another catastrophic event was the 1996 Nazca earthquake (6.4 Mw earthquake), which left a balance of 94,047 people and 12,700 homes affected. The population was isolated by landslides and the most affected areas were Pisco, Palpa and Ica [3].

The need to know the seismic hazard of a certain sector generated great curiosity to determine which are the most optimal parameters to be used in various techniques that help with this purpose. In this sense, in Syria a numerical classification scheme was developed to identify parameters that allow the assessment of seismic hazard in a GIS environment. These indicators were based on: historical seismicity, tectonic characteristics, topography and slope [5]. Likewise, in Indonesia the seismic hazard was estimated based on territorial parameters such as: slope, curvature, elevation, lithology, amplification factor, distance from faults, fault density, distance from the epicenter, among others. These parameters were used in a machine learning environment (i.e., neural network) and hierarchical analysis [6]. Along the same lines, geological, geodetic, geotechnical and geophysical parameters were used in Tabriz, Iran to be able to build a seismic microzoning map to indirectly assess the current level of 
seismic hazard in the sector [7]. In addition, parameters related to demographic, environmental and physical criteria were also used for this purpose in a neural network approach. The territorial parameters that stand out the most in this research are slope, elevation and geology [8]. Similarly, failure parameters such as impact, fall, trail, slip, location, maximum and minimum depth can also be used to indirectly assess the level of seismic hazard [9].

On the other hand, at the national level, territorial parameters obtained through satellite images (i.e., digital elevation models, topography, etc.) are also used to estimate the level of hazard [10]. Similarly, Matsuoka et al. [11] propose the use of parameters obtained through satellite images accompanied by field data and censuses to indirectly estimate the seismic hazard in Peru through a GIS environment. In the same way, Lazarus [12] proposes the use of surveys with technical sheets and satellite photographs to map the seismic scene of the place. Similarly, the Japanese Peruvian Center for Seismic Research and Disaster Mitigation (CISMID) [13] proposes visual evaluation sheets (building material, number of floors, predominant structural system, etc.) complemented with photographs contrasted to a GIS database for the mapping of seismic microzoning and seismic hazard analysis. Thus, various studies focused on seismic zoning activities used political-administrative, physicalgeographic, socio-demographic, economic-productive and functional criteria [14]. Finally, according to Matsuzaki et al. [15] it is possible to obtain parameters based on data from damage survey, seismic movement simulation, ground conditions and damage rate for each zone.

Consequently, it can be observed that there is no consensus on which set of parameters is the most optimal to determine the level of seismic hazard. However, common aspects of these projects lie in the so-called territorial conditions. The latter due to the possibility of implementing various techniques (i.e., hierarchical analysis, machine learning, GIS environments, etc.) and the availability of information. Therefore, this study shows an extensive bibliographic review accompanied by an analysis of the study area to be able to determine a set of - applicable and reproducible - parameters that allow an adequate and coherent evaluation of the level of seismic hazard at different territorial scales.

The rest of the article is organized as follows: After this first introductory section, Section 2 presents the research methods, including the collection and processing of information, the definition, selection and analysis of criteria to choose the set of parameters that allow assessing the level of seismic hazard; Section 3 reports the results obtained, while, in Section 4, we present an in-depth discussion of them. Finally, the conclusions are shown in Section 5.

\section{METHODOLOGY}

The objective of this work is focused on determining a set of territorial parameters that allow an adequate identification of the level of seismic hazard. For the methodological implementation, the city of Pisco was chosen as a case study. Fig. 1 shows the methodological framework designed to fulfill this purpose.

\subsection{Data gathering}

This project focuses on a comprehensive review of the literature on how territorial parameters can help identify the level of seismic hazard of a given area. At the local level, the most relevant research corresponds to that carried out in 2001 by INDECI [14] whose objective was to determine the hazard levels of Pisco categorized into 4 levels (i.e., very high, high, 


\section{IDENTIFYING PARAMETERS TO DETERMINE THE LEVEL OF SEISMIC HAZARD BASED ON TERRITORIAL CONDITIONS}

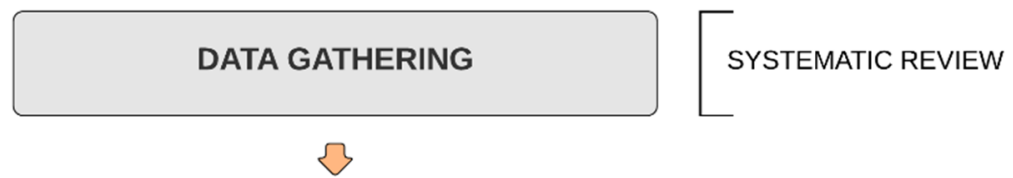

SET OF TERRITORIAL PARAMETERS

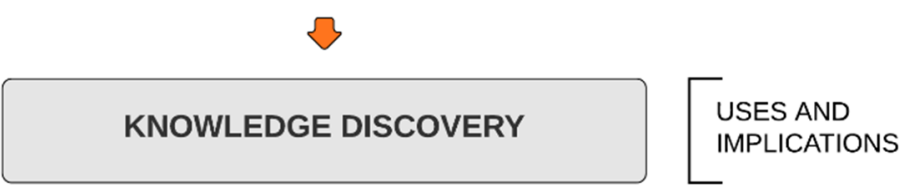

Figure 1: Methodological framework.

medium and low) using territory parameters such as the water table, soil type and slope. However, these parameters and hazard classification cease to have effect when an event reoccurs and site considerations change [16]. At the international level, Table 1 shows the summary of the most relevant revised bibliography for determining the level of hazard.

\subsection{Proposal of territorial parameters}

This section explains the process for selecting the territorial parameters that were considered in this proposal. To obtain the final proposal of the territorial parameters set, different bibliographic sources were studied to subsequently select the most appropriate literature with the most influential parameters. Following that, territorial parameters were proposed for the Pisco area, considering criteria such as accessibility and information availability. For this, the research developed by Birkmann was taken as a main reference [18] which mentions that for a parameter to be influential it must be reproducible, robust, reliable and easy to measure. In this sense, the result of this adaptation led to the determination of a set of parameters that will be presented and discussed in later sections.

\subsection{Description of the case study}

The province of Pisco is located to the north of the province of Ica and to the south of the province of Chincha. Pisco has an area of $3,978 \mathrm{~km}^{2}$ and a population of 125,879 inhabitants according to the National Institute of Statistics and Informatics (INEI) [19]. In this sense, the district of Pisco has been selected as a case study not only because of its location in the coastal zone near the convergent edge of the plates, but also because it is continuously affected by earthquakes of different intensity, reinforcing the idea of that Pisco is one of the cities most affected by seismic movements [16]. Fig. 2 shows the location of the case study and Table 2 shows the history suffered, the 2007 earthquake being the event that has caused the most 


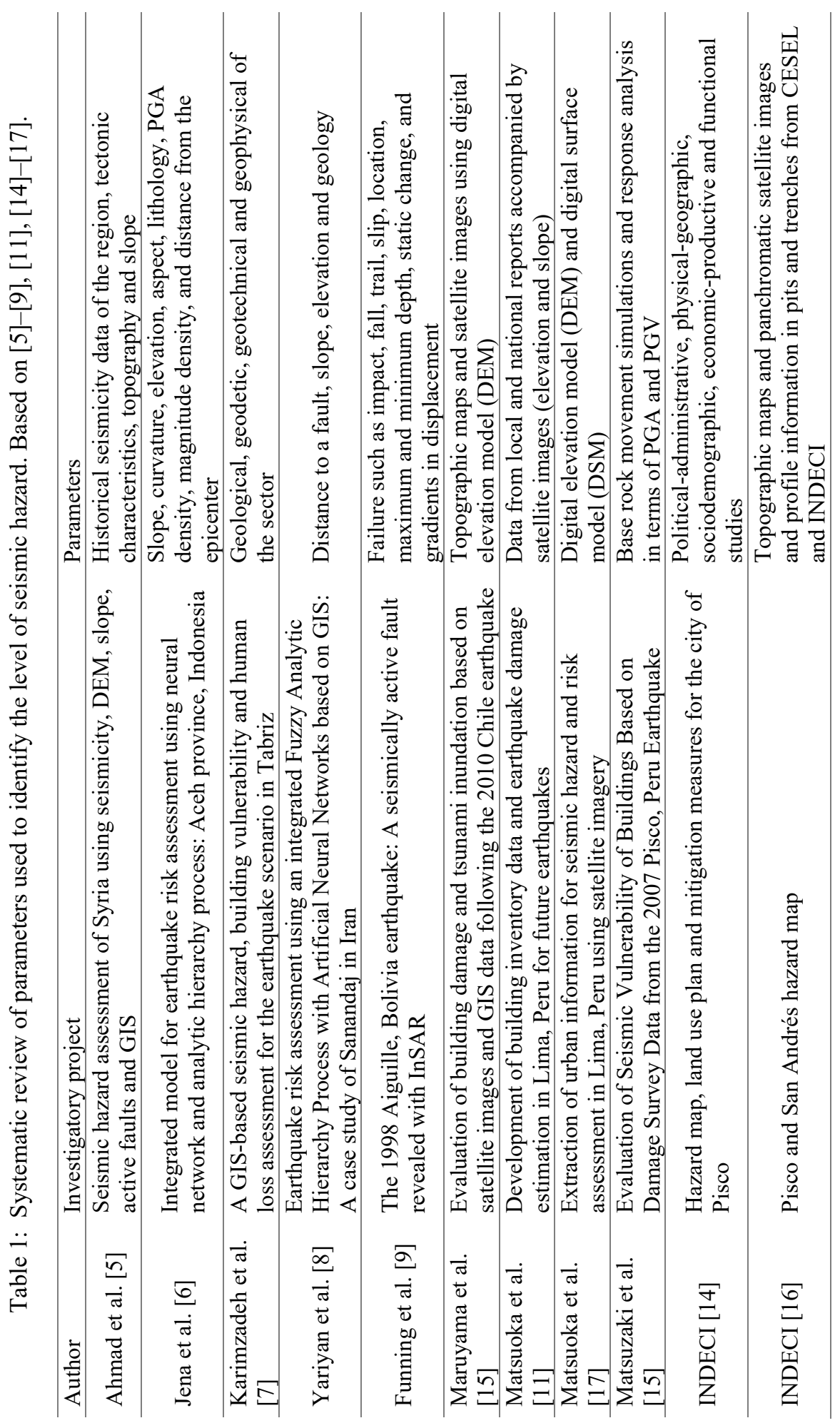



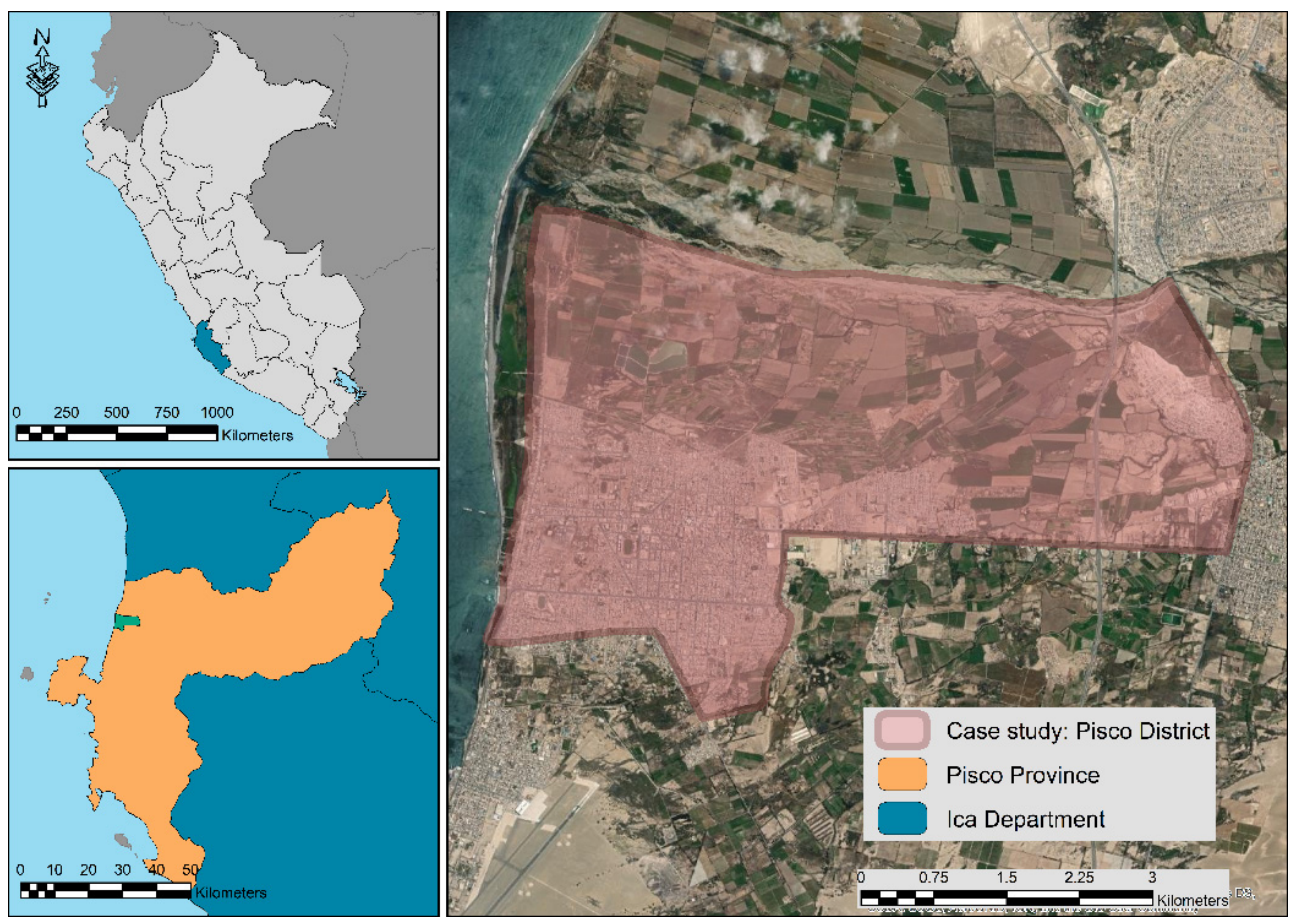

Figure 2: Case study: Pisco District.

Table 2: Record of seismic events in Pisco. Adapted from [16].

\begin{tabular}{|c|c|c|}
\hline Date & Intensity & Location \\
\hline $05 / 12 / 1664$ & VIII & Pisco \\
$03 / 30 / 1813$ & VIII & Ica \\
$11 / 21 / 1901$ & IV & Ica \\
$02 / 23 / 1907$ & V & Ica \\
$09 / 11 / 1914$ & IV & Ica \\
$09 / 20 / 1915$ & V & Ica \\
$10 / 07 / 1920$ & V & Ica \\
$10 / 11 / 1922$ & IV & Ica \\
$08 / 24 / 1942$ & IX & Ica \\
$09 / 29 / 1946$ & VII & Pisco \\
$12 / 09 / 1950$ & VII & Pisco \\
$04 / 04 / 1951$ & IV & Ica \\
$01 / 15 / 1960$ & VII & Ica \\
\hline
\end{tabular}

\begin{tabular}{|c|c|c|}
\hline Date & Intensity & Location \\
\hline $01 / 15 / 1960$ & IV & Ica \\
$01 / 27 / 1961$ & VI & Ica \\
$09 / 28 / 1968$ & VI & Pisco \\
$09 / 28 / 1978$ & V & Ica \\
$10 / 20 / 2006$ & VII & Ica \\
$10 / 26 / 2006$ & VI & Ica \\
$08 / 15 / 2007$ & VII & Pisco \\
$10 / 28 / 2011$ & VII & Ica \\
$01 / 30 / 2012$ & VI & Ica \\
$05 / 06 / 2012$ & VI & Ica \\
$03 / 15 / 2014$ & VI & Ica \\
$10 / 19 / 2016$ & V & Ica \\
$01 / 16 / 2021$ & V & Ica \\
\hline
\end{tabular}

damage [20]. Among the main losses generated are 59,971 victims, 383 deaths, 50,522 homes affected and multiple damages to critical infrastructure [2]. The most relevant feature of this event was its long duration [21] revealing the need for an updated study of hazards conditioned by the susceptibility of the territory [22]. 


\section{RESULTS}

After processing and analyzing the information obtained from the study of the relevant literature (Table 1), we propose as territorial parameters the type of soil, slope and soil liquefaction. Also, it is important to mention that these parameters show adequate potential to study the seismic hazard present in the sector and that not only can they vary over time, but also according to the study area since each area of interest has different geomorphological characteristics among other peculiarities [6]. Finally, each proposed parameter is described below.

\subsection{Soil type}

The city of Pisco is made up of sedimentary rocks and quaternary deposits. Recent accumulated quaternary deposits consist of thick conglomerates interspersed with sand, silt and clay [23]. According to Walsh [24], after a soil study in Pisco, determined that the soil in the area exhibits a sandy texture (loamy sand with a loose consistency) and low water retention capacity. According to the research carried out by INDECI and INGEMMET [16], the area is composed of white diatomite interspersed with silt - whitish clays and sand with particles of different sizes, but with a very small amount of fines, for which the cohesion tends to zero. On the other hand, these deposits are made up of poorly classified beach sand; almost always saturated with water and, therefore, have poor mechanical characteristics. At the same time, this sector is made up of landfill and rubble. Likewise, the CISMID [25] states that the soil of Pisco is made up of loose silty sand with semi-loose silty sand strata. In the same way, Pisco shows a problem of chemical aggressivity in the soil, because it is close to the coast. Fig. 3 shows the distribution of land types in the sector of interest.

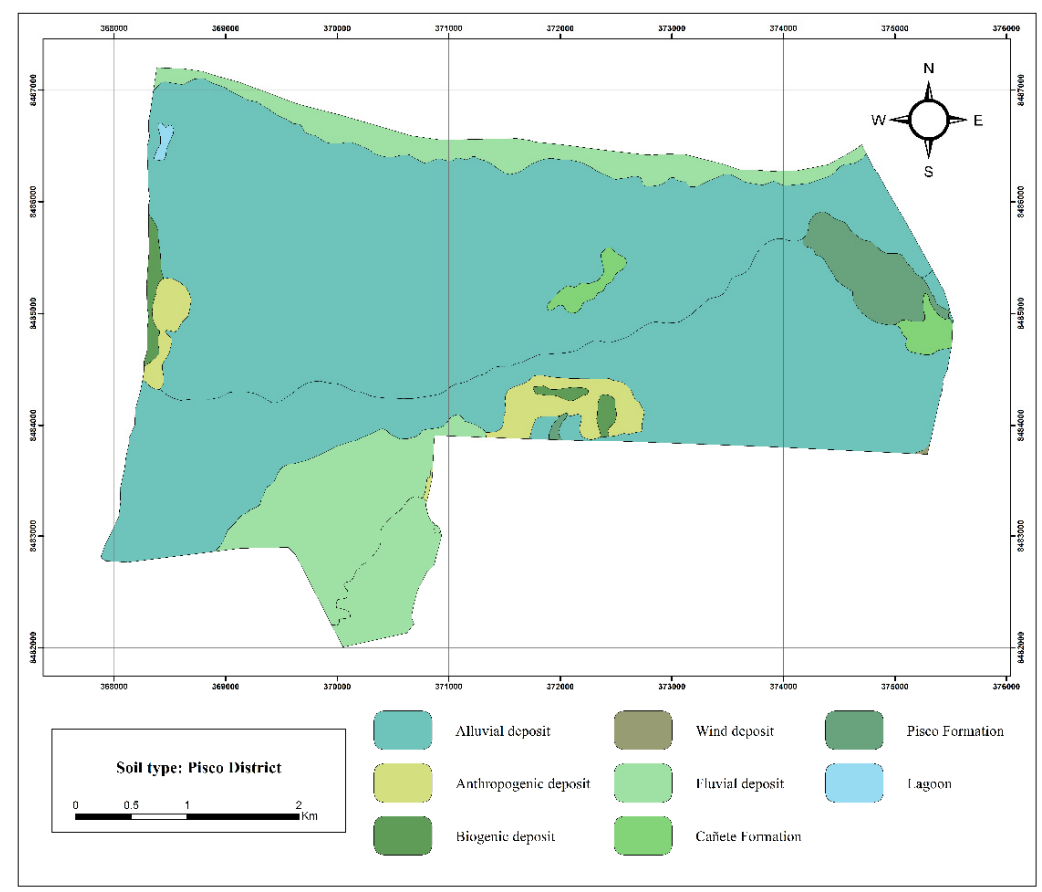

Figure 3: Soil type map: Pisco District. 


\subsection{Slope}

The study area is made up of a marine plain on which wind materials have been deposited. The surface presents slopes of less than $9 \%$ with steep sectors that reach slopes of up to $35 \%$. The relief is flat, moderately inclined [24]; that is, the elevation profile of the area represents a sector with a slight slope. Fig. 4 shows the mentioned characteristics of the sector.

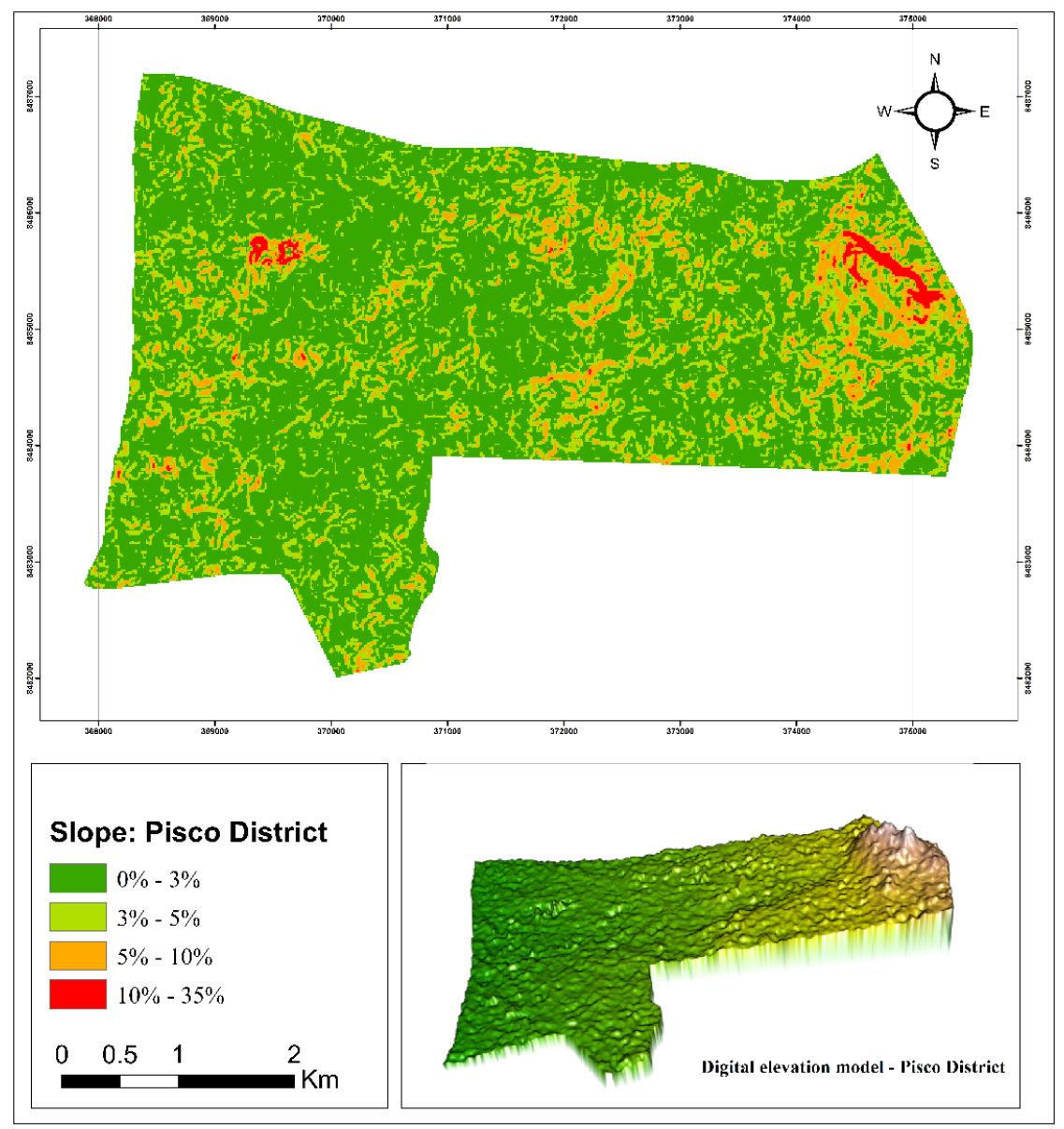

Figure 4: Distribution of slopes: Pisco District.

\subsection{Soil liquefaction}

Soil liquefaction is a phenomenon in which soils, due to water saturation (i.e., water table) and particularly soils such as sand or gravel, lose their resistance and flow as a result of the stresses caused in them due to seismic events; that is, during a seismic event, the pore water pressure increases in the subsoil and the effective effort is reduced until causing the pore water pressure to equal the total effort and the effective effort becomes zero $\left(\sigma^{\prime}=0\right)$. The latter implies that the soil loses resistance and behaves like a fluid [26]. On the other hand, 
although there are almost no bibliographic references of the geotechnical characteristics of the sandy soil in the Pisco area, we can deduce analytically how the reduction of the bearing capacity $\left(q_{a d m}\right)$ of the land was, which can be determined from the load capacity $\left(q_{u}\right)$ with Terzaghi's general expression [27].

\section{DISCUSSION}

For all the above, the sandy soil of Pisco always had a high liquefaction potential and, as a result of the 2007 earthquake, the loss of bearing capacity increased, which resulted in the outcrop of water due to cracking and slab joints of the pavement, as well as small turns and subsidence of houses [28]. Low or no fines content implies that the bearing capacity of the natural sandy soil is low, and this is further aggravated when the sandy soil is submerged. Carrillo and Alcayhuamán [28] and Rodríguez-Marek et al. [29] mention that, in Pisco, the sand deposits have an almost superficial water table. For this reason, this parameter has a great impact on the level of seismic hazard associated with the sector [30], [31]. Although it is true, after the Pisco earthquake in 2007, the E030 standard was modified to reinforce the houses in the area and make them less vulnerable [32]. There is no evidence of any type of soil improvement in the area. Therefore, considering that Pisco is exposed to experiencing liquefaction of its soils, it is important to determine which are the areas with the greatest predisposition.

On the other hand, the study sector, having a flat and relatively even slope, is prone to experiencing a tsunami in the event of a seismic event of considerable magnitude because it is located on the convergent edge and close to the sea. The implication of this parameter implies that, in semi-flat terrain, the penetration of the wave can be extensive; however, as it progresses, the wave height decreases due to the existing friction forces. Therefore, considering the implications that this may have on the conditions and livelihoods of residents, it is important to take it into account in a seismic hazard assessment [14].

Finally, it is important to mention that seismic waves travel through different types of soils. In the case of Pisco, the predominant soil is sandy (soft soil), which amplifies the waves and causes strong vibrations, causing the soil to experience liquefaction effects, differential settlements and resonance effects, leading to instability, collapse, and damage to buildings [33]. Likewise, the type of soil in the study area made up of sands and water tables causes the phenomenon of soil liquefaction to occur in the event of a seismic event. If the soil of Pisco were made of solid rock, this phenomenon would not occur and the consequences would be less lethal [34]. Likewise, in view of the fact that the cohesion of this type of soil tends to zero and, in turn, this parameter is a function of shear resistance, which would represent the absence of soil rigidity and large deformations [35].

\section{CONCLUSION}

This research determined a set of territorial parameters that influence the level of seismic hazard in a sector of interest through a vast bibliographic review and data from the study area. These parameters are soil liquefaction, soil type, and slope. Thus, it was identified that the Pisco area presents a semi-uniform relief with a type of sandy soil with very little amounts of fines, which generates a high susceptibility to soil liquefaction. Therefore, the effective stress would increase and, despite the rigidity of the structure, would cause subsidence and differential settlements, generating economic and human losses. On the other hand, considering that the type of soil will remain constant with minimum cohesion under normal conditions and that the slope will have a minimum percentage of variation due to erosion and human action, it would be important to work on establishing soil improvement strategies (i.e., injection by compaction) to reduce the liquefaction potential of the sector. Finally, this 
research is presented as a starting point for future research works that will implement and validate the parameters analyzed in this proposal.

\section{ACKNOWLEDGEMENTS}

This project was funded by Universidad Tecnológica del Perú, within the framework of the "Research Projects I+D+i 2021 - 1" agreement. The authors would like to thank José Zevallos and Yustin Yepez for their valuable comments on the previous version of this manuscript.

\section{REFERENCES}

[1] Tavera, H., Seismic Risk. Peru, A Highly Seism Country, 2019.

[2] OPS, Earthquake in Pisco, Peru - Two years after the quake, chronicle and lessons learned in the health sector. Lima, 2010.

[3] INDECI, Earthquakes in Peru over time. 2006.

[4] INDECI, Hazard map, mitigation program and disaster mitigation measures for the cities of Yungay and Ranrahirca. 2005.

[5] Ahmad, R.A., Singh, R.P. \& Adris, A., Seismic Hazard Assessment of Syria using seismicity, DEM, slope, active faults and GIS. Remote Sensing Applications: Society and Environment, 6, pp. 59-70, 2017. DOI: 10.1016/j.rsase.2017.04.003.

[6] Jena, R. et al., Integrated model for earthquake risk assessment using neural network and analytic hierarchy process: Aceh province, Indonesia. Geoscience Frontiers, 11, pp. 613-634, 2020. DOI: 10.1016/j.gsf.2019.07.006.

[7] Karimzadeh, S., Miyajima, M., Hassanzadeh, R., Amiraslanzadeh, R. \& Kamel, B., A GIS-based seismic hazard, building vulnerability and human loss assessment for the earthquake scenario in Tabriz. Soil Dynamics and Earthquake Engineering, 66, pp. 263-280, 2014. DOI: 10.1016/j.soildyn.2014.06.026.

[8] Yariyan, P., Zabihi, H., Wolf, I.D., Karami, M. \& Amiriyan, S., Earthquake risk assessment using an integrated fuzzy analytic hierarchy process with artificial neural networks based on GIS: A case study of Sanandaj in Iran. International Journal of Disaster Risk Reduction, 50, 2020. DOI: 10.1016/j.ijdrr.2020.101705.

[9] Funning, G.J., Barke, R.M.D., Lamb, S.H., Minaya, E., Parsons, B. \& Wright, T.J., The 1998 Aiquile, Bolivia earthquake: A seismically active fault revealed with InSAR. Earth and Planetary Science Letters, 232, pp. 39-49, 2005.

DOI: 10.1016/j.eps1.2005.01.013.

[10] Maruyama, Y., Yamazaki, F., Matsuzaki, S., Miura, H. \& Estrada, M., Evaluation of building damage and tsunami inundation based on satellite images and GIS data following the 2010 Chile earthquake. Earthquake Spectra, 28, pp. 165-178, 2012. DOI: $10.1193 / 1.4000023$.

[11] Matsuoka, M. et al., Development of building inventory data and earthquake damage estimation in lima, peru for future earthquakes. Journal of Disaster Research, 9, pp. 1032-1041, 2014. DOI: 10.20965/jdr.2014.p1032.

[12] Lazaro Barreto, M.R., Analysis of Hazards and Vulnerabilities for Disaster Risk Management, using the Geographic Information System (GIS) in the Town of Acopampa - Carhuaz, Ancash, Universidad Nacional Santiago Antunez de Mayolo, 2015.

[13] CISMID, Risk Analysis in Urban Areas of the Punta Negra District, vol. 2, 2017.

[14] INDECI, UNICA, Hazard Map, Land Use Plan and Proposed Mitigation Measures for the Effects of Natural Disasters in the City of Pisco, 2001. 
[15] Matsuzaki, S., Pulido, N., Maruyama, Y., Estrada, M., Zavala, C. \& Yamazaki, F., Evaluation of seismic vulnerability of buildings based on damage survey data from the 2007 Pisco, Peru earthquake. Journal of Disaster Research, 9, pp. 1050-1058, 2014. DOI: 10.20965/jdr.2014.p1050.

[16] INDECI, INGEMMET, CESEL, CONIDA, Hazard map of Pisco and San Andres information for reconstruction - Earthquake August 15, 2007. 2008.

[17] Matsuoka, M., Miura, H., Midorikawa, S. \& Estrada, M., Extraction of urban information for seismic hazard and risk assessment in Lima, Peru using satellite imagery. Journal of Disaster Research, 8, pp. 328-345, 2013.

DOI: $10.20965 /$ jdr.2013.p0328.

[18] Birkmann, J., Measuring vulnerability to promote disaster-resilient societies: Conceptual frameworks and definitions. Institute of Environmental Human Security Journal, 5, pp. 7-54, 2006.

[19] INEI. Ica: Final results. 2018.

[20] Tavera, H. \& Bernal, I., The Pisco (Peru) earthquake of 15 August 2007. Seismological Research Letters, 79, pp. 510-515, 2008. DOI: 10.1785/gssrl.79.4.510.

[21] Tavera, H., Bernal, I., Strasser, F.O., Arango-Gaviria, M.C., Alarcón, J.E., Bommer, J.J., Ground motions observed during the 15 August 2007 Pisco, Peru, earthquake. Bulletin of Earthquake Engineering, 7, pp. 71-111, 2009.

DOI: 10.1007/s10518-008-9083-4.

[22] Elnashai, A.S. et al., The Pisco-Chincha earthquake of August 15, 2007: Seismological, geotechnical, and structural assessments. 2008.

[23] Parra, D., Vasquez, D. \& Alva, J., Geotechnical microzonation of Pisco. CISMID UNI, 1, p. 19, 2015.

[24] Walsh., Environmental and social impact study "Peru Nitrates Project", 2006.

[25] CISMID, MVCS, Seismic microzonation study for the coastal areas of Pisco, San Clemente, Túpac Amaru, San Andrés and Paracas for the Coastal Areas of Pisco, San Clemente, San Andrés and Paracas Lima - March 2012. 2012.

[26] Braja M.D., Geotechnical engineering, 2001.

[27] Terzaghi, K., Bearing capacity. Theoretical Soil Mechanics, John Wiley \& Sons, Ltd., pp. 118-143, 1943. DOI: 10.1002/9780470172766.ch8.

[28] Carrillo, A. \& Alcayhuamán, L., Liquefaction of soils during the Pisco-Peru earthquake-2007. Universidad Ricardo Palma, vol. 9, 2007.

[29] Rodríguez-Marek, A. et al., Geotechnical aspects of the Pisco, Peru earthquake of August 15, 2007. Rev Int Disastr Nat, 7, 2007.

[30] Graf, E., Compaction grouting technique and observations. Journal of the Soil Mechanics and Foundations Division, pp. 1151-1158, 1969.

[31] El-Kelesh, A.M., Matsui, T., Tokida, K., Field investigation into effectiveness of compaction grouting. Journal of Geotechnical and Geoenvironmental Engineering, 138, pp. 451-460, 2012. DOI: 10.1061/(asce)gt.1943-5606.0000540.

[32] MVCS, National building regulations. Lima, 2018.

[33] Bernal, I., The effects of earthquakes on soil types 2020. https://www.gob.pe/ institucion/igp/noticias/309366-los-efectos-de-los-sismos-en-los-tipos-de-suelo. Accessed on: 8 May 2021.

[34] Tavera, H., Evaluation of hazards associated with earthquakes and secondary effects in Peru, 2014.

[35] Socualaya Cardenas, K., Soil characterization to obtain ballast coefficient. San Agustin de Cajas District, 2017. 